Article

\title{
Double Screen Innovation: Building Sustainable Core Competence through Knowledge Management
}

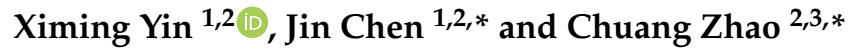 \\ 1 School of Economics and Management, Tsinghua University, Beijing 100084, China \\ 2 Research Center for Technological Innovation, Tsinghua University, Beijing 100084, China \\ 3 Jilin Provincial Development and Reform Commission, Jilin 130051, China \\ * Correspondence: chenjin@sem.tsinghua.edu.cn (J.C.); zhaoch.13@sem.tsinghua.edu.cn (C.Z.)
}

Received: 5 June 2019; Accepted: 4 August 2019; Published: 7 August 2019

\begin{abstract}
How to exploit the precipitated internal and external knowledge to build dynamic capability in the era of big data remains a big challenge for innovation and business sustainability. This paper documents a novel perspective to address this challenge by exploring the double screen innovation knowledge management practice in Commercial Aircraft Corporation of China Ltd. (COMAC). Drawing from the literature on knowledge management and knowledge-based view, this paper elaborates how the new type of knowledge management practice represented by the case of Double Screen Innovation (DSI) in COMAC could help enterprise build sustainable core competence, which provides new perspective for multi-level knowledge management towards business sustainability. DSI, as a novel way of knowledge management, optimizes the micro-level knowledge co-creation and sharing and macro-level organizational learning mechanisms to accelerate the knowledge accumulation and dissemination within the organization. The process of knowledge creation, transformation, and application helps to integrate and transform big data into useful business information, thus provides an endless driving force conducive to the establishment and promotion of the core competencies of enterprises.
\end{abstract}

Keywords: knowledge management; double screen innovation; knowledge-based view; business sustainability; core competence; Commercial Aircraft Corporation of China Ltd. (COMAC)

\section{Introduction}

Enterprises are the main engines of innovation and economic development [1], big data embedded with abundant knowledge empowers enterprises with huge potentials and sustainable corporate innovation resources [2,3]. With the rise and development of the knowledge economy [4], the advent of the era of big data $[2,3,5]$ and extensive applications of new knowledge management technology, such as enterprise resource planning (ERP) [6] and artificial intelligence [7], the environments of business operations and advances have also undergone significant changes [8-10]. Scholars have increasingly come to view knowledge as one of the most important resources necessary for competitive advantage and business sustainability, either for small and medium enterprises or mature enterprises [11-13].

However, Barley, Treem and Kuhn [11] pointed out in their recent review article that although knowledge management research in the past two decades has evolved from the shift toward the knowledge-based theory, one important step forward is to broaden our analytic scope to include a more dynamic vantage of managing knowledge in different organizational contexts. Especially for the startups, argued by Centobelli, Cerchione and Esposito [13], how a knowledge management system facilitates the knowledge management and its outcomes are remained to be seen. Therefore, how an organization effectively develops technological, structural strategies and systems to exploit 
the precipitated internal and external knowledge to build dynamic capability is still a challenge for corporate innovation and sustainability-oriented performance [3,11,13].

Here in this paper, we are trying to address this challenge by the focus on one key question, which is how to accelerate the process of knowledge creation, transformation, and implementation so that enterprises can form a sustainable innovation system, and finally build up sustainable competitive advantage [9,12]. We employ the case of the Commercial Aircraft Corporation of China (COMAC, Shanghai, China) in the civil aviation industry to explore the answers to this question.

The civil aviation industry is one of the most knowledge-, technology- and capital-intensive industries in the world. The aviation industry, which is called the pearl on the crown of manufacturing, has great capability to drive the development of companies upstream and downstream of the industry chain, creating a huge opportunity for new material application and the invention of new technologies. There are only a few countries in the world that can manufacture their own airplane, including the United States, France, Russia, Brazil, and China. As a crucial industry with a long history based on the military aviation development, the civil aviation industry has a large body of institutionalized, complicated, intangible, and discreet knowledge, which were mainly controlled by two leading companies: Boeing from US and Airbus from Europe.

COMAC was established in May 2008 in Shanghai, China. It aims to build an innovative organization to achieve domestic and international competitive advantage in the aviation industry and help reduce China's dependence on established major foreign players, such as Boeing, and Airbus. Continuous R\&D and innovation, COMAC resulted in the ARJ21 aircraft, which was first marketed in 2015. This was followed by the 168-seat C919-and its roll-out, and successful maiden flight, occurred in 2015 and 5 May 2017, respectively. The aircraft has generated interests from many airlines trying to compete in the market for single-aisle jets dominated by the Airbus A320 and Boeing 737. Not surprisingly, many policymakers and the public are interested in "the secret lessons" of COMAC's breakthrough innovation that was achieved in such a short period of time. The importance of studying managerial experience, knowledge and the mechanism from knowledge management to core capability is greater in an industry in which learning the key technologies, best practices, and dominant designs are difficult. Therefore, the key to understand COMAC's technological innovation is, how does it build sustainable core competence through knowledge management, and what lessons that other organizations can learn from it.

Drawing from the in-depth case analysis of COMAC, this paper focus on how enterprises build knowledge-based core competence through knowledge management. As a new practice of knowledge management, Double Screen Innovation (DSI), which entails the establishment of the second computer screen for knowledge creation, sharing and application within the organization, would generate a tremendous impact on the rapid development of learning mechanisms and the sustainability of the whole company.

This paper extensively explores the case of COMAC and proposes an interactive model of knowledge management that led to the company's success. This study not only contributes to the literature of knowledge management and knowledge-based view, but also provide important insights for the organization to incorporate big data opportunity into knowledge management process so as to build sustainable competitive advantage and obtain premium economic rent [14,15]. More specifically, the main contribution of this study is an inductive process model that put forward a new concept called Double Screen Innovation (DSI). This paper will clearly explain the special activity and practice of knowledge management, and how the DSI works in the implementation of knowledge management, also how those differences relate to ways in which knowledge resources are acquired and how they are used in practice to create distinctive competencies. In the course of developing the interactive knowledge management model, several new concepts with theoretical implications emerged. In particular, we propose the notions of the double screen innovation, knowledge engineering, and the systematization, contextualization, and intelligentization of knowledge. What's more, this study explains how organizations like COMAC build a new system of co-creating of knowledge within the 
organization, also puts up with the interactive model that explains how an organization accumulates and transfers the knowledge and then empowers individuals and teams at the micro-level. Thus, this study generates new insights into opening the "black box" between knowledge, knowledge management and innovation, so as provide a useful way to build sustainable core competence.

In the following sections, this paper first reviews the theoretical background and proposes the research question. Section 3 introduces the research methodology. Section 4 contains empirical analysis and main findings from COMAC's DSI mode. Section 5 discusses the research results, research limitations, and some propositions for future research. Section 6 concludes the study. Section 7 further discusses the implications.

\section{Literature Review and Research Question}

The goal of the firm is to use whatever resources that are available to achieve sustainable competitive advantage through technological innovation and management change $[3,11,13,16]$. Resources refer to all tangible and intangible assets possess by the enterprise that can be used to conceive of and implement strategies that improve its efficiency and effectiveness, such as assets, capabilities, organizational process, firm attributes, information and knowledge [16,17]. The resource-based view (RBV) predicts that as strategic resources are heterogeneously distributed across firms and these differences are stable over time, the firm who wants to build core competencies and achieve sustained competitive advantage must own resources that that are valuable, rare, imperfectly imitable and non-substitutable. More specifically, as Barney [16] puts it, "a firm enjoys a competitive advantage when it is implementing a value-creating strategy not simultaneously implemented by large numbers of other firms". So, a firm with a better organizational process that can exploit its assets would enjoy the advantage of core competence building and achieve a sustained competitive advantage.

While the resource-based view predicts strategic resources are crucial to corporate innovation and core competence, knowledge-based view (KBV) goes further and argues that the core element of resources should be knowledge, including tangible and intangible knowledge, as well as the way how firms should be organized for them to generate and exploit knowledge [12,18,19]. Increased attention is being paid to the importance of big data, knowledge, and the role of knowledge has been gradually established as one of the key competitive resources and foundation of professional capability enhancement $[5,9,20]$. Similar to the resource-based view [21], the knowledge-based view also holds a foundation and hypothesis that knowledge is largely tacit and grounded in a unique historical, social, and cultural context. As such, it can be a source of sustained competitive advantage, because such knowledge is quite difficult for competitors to imitate and acquire freely in markets [16].

Although the resource-based view and knowledge-based view have developed rich conceptual arguments rapidly in recent years, knowledge management (KM) scholars realize that it is still a big challenge for firms to integrate and transform data into useful innovation resources, and for them to create, acquire, and apply knowledge for sustainable firm innovation and performance $[5,11]$. Current literature of knowledge management has investigated a multiple of factors in knowledge management, including organization level [22,23], individual level [24], and the impact that industry or environment relationships have on a firm's knowledge management [25].

These research findings provide both scholars and managers with novel perspectives on how, when and where to conduct knowledge management to achieve better product, technological and corporate performance $[11,13,26]$. However, the current scholarship on knowledge management and KBV has privileged particular trajectories of knowledge over others, which needs a broaden and dynamic perspective to explore how could firms utilize knowledge management in the complex contexts and use knowledge management as a tool to drive organization change for sustainable innovation [11,22]. Especially in situations when firms are new players in the industry with complex products or projects [27], such a firm needs to accumulate knowledge and enhance its learning mechanism system to shape the market $[3,6,18]$. Innovation in knowledge-based organizations is particularly challenging owing to the ambiguous nature of knowledge itself, let alone the unstructured 
nature of big data [18,28]. Bhatt [22] points out that knowledge management process can be categorized into knowledge creation, knowledge validation, knowledge presentation, knowledge distribution and knowledge applications activities, while only by creating a nurturing and "learning by doing" kind of environment could a firm sustain its competitive advantages.

Then, the crux of the matter is: How should managers utilize knowledge to create core competencies, especially in an industry with knowledge- and capital-intensive nature and only a few rivals predominating the industry? We set out to understand the mechanism of knowledge transferring into core capability, the capability-building framework of knowledge management, and the processes that top managers, medium executive officers, and employees on-site use to transform common knowledge into a professional capacity establishment that can create distinctive and core capabilities.

\section{Research Methodology}

As this work is based on an in-depth case study of COMAC's new type of knowledge management practice, we followed the metatriangulation strategy proposed by Lewis and Grimes [29] and applied the case study research design and analysis approach followed Robert Yin [30], Strauss and Corbin [31], Miles, Huberman, and Saldaña [32]. Then we employed multiple data sources and rigorous analytic approach by Yin [30], Glaser [33] and Eisenhardt [34] to explore the knowledge management practice in COMAC and the insights on knowledge management stemming from the COMAC case.

\subsection{Multiple Data Sources}

\subsubsection{Sampling}

We first use the sampling approach by Yin [30] to select the key persons in the relevant department related to our research question. This form of sampling is different from random sampling in the sense that the persons or departments selected as informants represent both their own thoughts and the departments to which they belong. Out of the more than twenty people in the sample, seven were from the headquarters, eleven were from Shanghai Aircraft Manufacturing Company, and two were from Shanghai Aircraft Design and Research Institute. We tried to develop a close working relationship with them during a two-week deep dive investigational and research period. Significant measures and steps were taken to ensure that the sample represented the broad segments of COMAC in terms of industry features, knowledge acquirement, technology-learning, knowledge management, and capability-building.

\subsubsection{Interviews}

In November 2015, our research started with an interview with the General Manager, He Dongfeng. In April 2017, after over two weeks of full-day investigations and half a year of surveys at COMAC, we finished 24 interviews involving five different departments and twenty working groups. Five interviews were in the top management team, including the general manager, senior managers, and other key members; the remaining interviews were conducted with employees in different departments. We also interviewed university professors and industry experts to develop an understanding of the strategic and technological issues facing the industry. In addition, we had in-depth talk with the Director of the Department of Science and Technology, meeting with General Manager, Director of the General Office of COMAC, Vice President of Shanghai Aircraft Manufacturing Co. Ltd. (Shanghai, China), and General Technician of Shanghai Aircraft Manufacturing Co. Ltd. All these interviewees are senior executives and experienced staff playing key roles in strategic or operational activities. We also interviewed other typical employees identified by the Human Resource Department's executives. We spent extensive time on observations and engaging in impromptu talks with front-line employees, gaining perceptual knowledge of the manufacturing process and the complexity of innovation. Moreover, we took chances to attend the organized group discussion 
sessions with the Advanced Technology Working Division and some regular working meetings in the Department of Science and Technology. These discussions helped us understand the data and acquire more thorough insights into the company's innovation process.

We followed a semi-structured interview protocol, focusing on challenges and the learning mechanism, motivation, executive situations, and the innovation management system. Questions also include the interviewees' beliefs about the features of COMAC, the sources of competitive advantage and innovation system in the industry, and the role of know-how and expertise in developing these sources. Thereafter, we asked how they make decisions and take actions in daily work and the role that know-how and expertise played in these decisions and actions. Last, but not least, this survey posed many questions about the enterprise culture, which is believed to have a long-lasting and deep influence on comparative advantages. During the data collection process, to increase the credibility of the data provided by our interviewees, we asked them to provide concrete examples or accurate evidence to support their commentary about the specific measurement of knowledge management and the role of know-how and expertise in the creation of competitive advantage. Also, this paper would clarify some doubts using some other sources in the firm. This approach allowed us to achieve confidence in ascribing trustworthiness to the interviewees' claims, which was particularly important for information about specific actions, action patterns, and their true impact in practice.

\subsubsection{Archival and Other Sources}

In addition to the interview data, the authors also collected archival data in the form of published news, magazine articles and research articles published in Chinese academic journals from the platform of China National Knowledge Infrastructure (CNKI), using the keywords COMAC, big plane, civil plane, and etc. We used the archival data primarily to get an in-depth understanding of the strategic challenges affecting the aviation industry, to gather additional information and challenges related to COMAC's innovation. Before we undertook the two-week deep-dive, we had gathered a lot of fundamental information and data about the aviation industry and the COMAC, which provided a solid foundation for surveys and research.

\subsection{Research Approach}

Consistent with the interpretive research approach, we relied primarily on the knowledge of executives of seven departments within COMAC and its controlled companies. Both data collection and interviews are conducted in this research. Although an interpretive approach might have some biases in the sense of the uncertainty caused by the interviewees, with independent judgment, it is good to assume the task of further interpreting and structuring the statements of the interviewees in light of both contextual factors and prior theorizing [31], thus casting them in theoretical terms to develop an inductive model. Given the main research question, we concentrated on exploring the working mechanism of knowledge management.

\subsection{Analytic Approach}

We began to analyze the results at the same time when collecting the interview data within the company. We cycled between data analysis and consultation with relevant literature as guides to theme development and subsequent data collection. Drawing on Miles and Huberman's [32] and Yin's [30] suggestions for analyzing data from multiple sites, we began by analyzing the details of each survey, via on-site analysis. The purpose of utilizing this approach was to compare emergent categories from different sources. We read each interview several times, trying to discern similarities and differences among interviewees and sites and relied on constant comparison across multiple interviewees to detect concept patterns [33].

As raw codes that were similar or related were discerned, we combined them into first-order categories, making sure to employ the language used by the interviewees whenever possible. This approach helped develop a relatively grounded theoretical framework that linked the various 
concepts emerging from the data. Taking a cue from recent work on charting the emergence of knowledge-based structures and practices in organizations [18], we paid particular attention to the linkages and relationships among concepts while analyzing the data. The main outcome of the analysis is a process model that clarifies how managers and employees collect raw sources of knowledge and use their knowledge to promote firm's professional capability and core competence, transforming common knowledge through uncommon knowledge-utilization practices. Throughout the process, we endeavored to seek the comments and feedback from the interviewees to improve the draft's framework, viewpoints, and conclusion. This approach also benefited the overall analysis process and increased the rigor of the framework.

\section{Analysis, Main Findings and Results}

\subsection{Overview}

The second screen campaign, as a knowledge management project, is run by the Technical Center, Department of Science and Technology Management and manufacturing plant to promote the comprehensive capability of COMAC, aiming at building professional capability among staffs, actions taken include the establishment of an electronic library, the creation of a platform for knowledge applications, and the promotion of the intelligent services of knowledge. The second screen refers to employees adding a new computer screen for information gathering, data reference, and knowledge support for their normal work so as to improve employee performance, refine the company's knowledge system, and create a learning organization. In doing so, this will lay the foundation for building the company's core competencies and sustainable competitiveness. COMAC's new type of knowledge management, namely DSI (double screen innovation), can be seen below in Figure 1 .

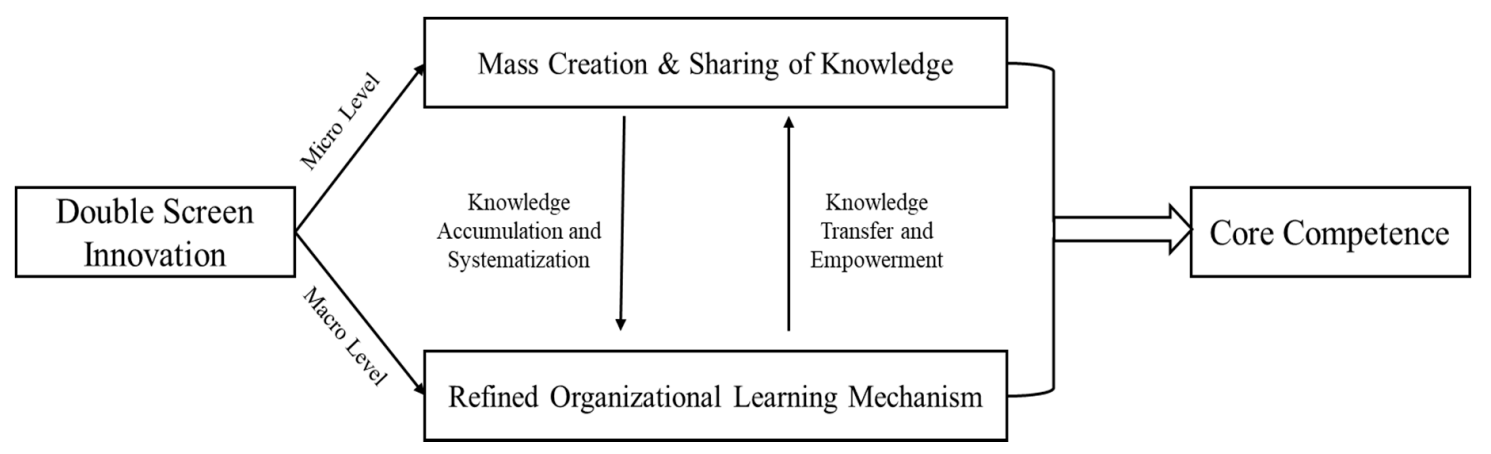

Figure 1. Mechanism of Double Screen Innovation (DSI)'s impact on core competence.

DSI is a knowledge management project with the establishment of the second working computer screen for individual employees, but not just to provide a second screen for employees. Its essence lies in the optimization and innovation of corporate knowledge management system, which helps to form an interactive model of co-creation and sharing of knowledge, as well as an improvement in the organizational learning process beneficial to core competence. At the micro-level, the DSI enables each employee to access the structural knowledge database of the entire company, thus can have more scientific and efficient solutions to the problems encountered in their daily work. What's more, employees have a sense of participation and truly enjoy innovative performance enhancements through the knowledge system-building process. Based on this shared participation and co-creation at a micro level, the DSI is meant to optimize the corporate learning atmosphere and organizational learning mechanism. Knowledge accumulation and systematization are achieved by the questions and solutions upload by each knowledge workers through their second working computer screen. In turn, the knowledge engineers at the organizational level could help to standardize the modulation of knowledge, digitalize the knowledge base and provide a powerful structural tool to transfer knowledge and empower individuals to improve work efficiency and quality. 


\subsection{Phases of DSI}

While Figure 1 shows the interactive mechanism about the DSI's impact on core competence, DSI is actually a complex process that consists of three main phases. Based on the interviews within COMAC, the double screen innovation mainly includes the three aspects, as shown in Figure 2.

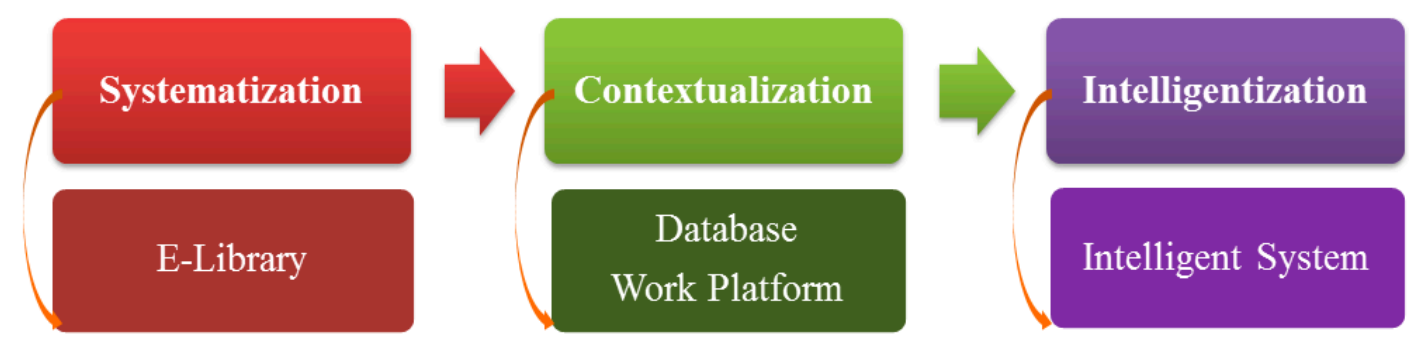

Figure 2. Three main aspects of Double Screen Innovation (DSI).

4.2.1. Knowledge Engineering-The Establishment of Electronic Libraries to Achieve the Systematization of Knowledge Building

The first step of double screen innovation is to achieve the knowledge repository of the knowledge that shows on the second screen, which entails the establishment of an electronic library of structured knowledge, and then using the knowledge and materials as fixed assets to "make hidden knowledge explicit and explicit knowledge systemized." For example, COMAC spends plenty of resources on the preparation of the task and process manual, the preparation of historical knowledge, and tacit knowledge collections. At the same time, the knowledge management system should be established to match with other systems, such as the assessment and incentive system. Through the pilot projects carried out by some units, their useful experience was refined so as to better promote the implementation of standardization and systematization of knowledge, laying a solid foundation for the company's follow-up knowledge applications, knowledge inheritance, and job training.

4.2.2. Problem-Oriented-To Serve Product Manufacturing and Achieve the Contextualization of the Knowledge Application

The collection of knowledge is for the application of knowledge. The systematization of knowledge is to better apply it to real-world situations and practical problems to achieve production goals. Based on the database of assets, the formation of a working platform combines the systematization of knowledge with work processes according to different circumstances. Doing so allows the working platform to standardize the modulation of knowledge, using the fragmented assets directly to improve work efficiency and quality. For example, in the case of the Shanghai Aircraft Manufacturing Company, after applying the double screen innovation program and platform, the average time needed for a design tool was shortened from the original 22 business days to 14 days, equating to a $36 \%$ increase in efficiency. At the same time, problem-oriented contextualization of the knowledge application is also beneficial to continue improving the knowledge management system so that problem-oriented knowledge processing and integration work could become the work norm.

4.2.3. Smart Enterprise-To Enhance the Core Competence of Enterprises and Achieve the Intelligentization of Knowledge Services

The term intelligence has been used by researchers in artificial intelligence since the 1950s, then business intelligence became a popular term in the business in the 1990s, while recently the terms business intelligence and analytics (BI\&A) and big data analytics (BDA) rose to popularity in the management studies $[10,35,36]$. The ultimate goal and vision of double screen innovation is to achieve the intelligent function of data and knowledge, such as intelligent decision-making mechanism and intelligent error correction method. As a kind of integration innovation, it is an intelligent usage of knowledge processing capacity. In the process of manufacturing, intelligent 
knowledge management systems help employees by providing a scientific operating program and reference system so as to empower them to make better scientific decisions during the implementation process. The implementation from the process to end will also be bolstered with automatic error correction function, with some good examples for reference at the same time. With the help of AI (artificial intelligence) and big data technology, intelligent knowledge systems today often possess self-learning functions, constantly optimize algorithms, evolution, and development to enhance their intelligence level.

\subsection{Framework of the Findings}

To elaborate the process of DSI more clearly, we try to discuss each of these elements of the three phases of the DSI from the raw materials of interviews and abstract the typical notes demonstrating the main ideas of the managers or the employees. Table 1 shows data that led to the development of all the second-order themes and aggregate dimensions, providing a glance of how the mechanism works.

\subsection{Small Case}

To illustrate the process more vividly and tangible, the author will illustrate the subject matter through a small case of what might happen in the daily operations for the engineers at COMAC. In a typical day, when an engineer is asked about production issues or problems in the field, he or she would pose many questions and go directly to the site and investigate the real problem. Then, he or she might have ideas and some initial judgments before returning to the office and referring to various books and historical materials to carry out some in-depth research concerning the problem. This process is very typical, as the professionalism of an engineer requires strong corroboration for his or her judgments.

With the DSI after the second screen construction, the engineer could query about the problem in the system by entering some keywords, then he or she would receive a plethora of information, references, and some choices for dealing with the current problems before heading to the field. With strong guidance and several potential solutions to the problems in mind, he or she would gain inspiration and insights and be able to make a decisive decision. The problem is likely to be dealt with much more effectively and efficiently, compared to the traditional methods. After he solves the problem, he could upload his comments, feedbacks and insights from his practice through the second computer screen as a new source of knowledge for other peers. The platform in which the business intelligent analytics tool is embedded will further archive this kind of unorder data and classify his feedback, then updates the old solution for similar problems. In this way, the double screen knowledge platform empowers a dynamic closed-loop of mass creation, sharing and transferring of knowledge within the organization.

\subsection{Model of DSI}

We attempt to integrate all of the innovative factors and the resulting mechanism into a whole figure that can show the phases of DSI, its theoretical logic, and the linkage between the best practice in knowledge management and core competence-building at COMAC.

Based on the double screen innovation knowledge management model (see Figure 3), internal and external knowledge is collected to meet the needs of core competence. Then, the standardized, structured, and systematic knowledge base is formed through the process of filtering and coding. As a problem-solving and application-oriented system, it realizes the contextualization and intelligentization of knowledge through the transfer from knowledge-based to sharing applications. The double screen innovation uses the SECI model, which consists of socialization, externalization, combination and internalization [8] as its micro-foundation. This kind of circle of knowledge creation and transformation provides a steady and sustainable stream of power to drive corporate core competencies-building and enhancement. 
Table 1. Representative quotes showing the process of DSI and the aggregate dimensions.

\begin{tabular}{|c|c|c|}
\hline First-Order Categories & Second-Order Categories & Aggregate Dimension \\
\hline \multirow{3}{*}{ Knowledge Engineer } & Second screen construction is essentially knowledge engineering. & \multirow{10}{*}{$\begin{array}{l}\text { Systematization of } \\
\text { Knowledge Building }\end{array}$} \\
\hline & Knowledge accumulation needs to be done step by step. & \\
\hline & Second screen construction requires planning and scientific strategy. & \\
\hline \multirow{3}{*}{$\begin{array}{l}\text { Making the Hidden } \\
\text { Knowledge Explicit }\end{array}$} & $\begin{array}{l}\text { Operational knowledge, management knowledge, technical } \\
\text { learning and other knowledge are archived. }\end{array}$ & \\
\hline & $\begin{array}{l}\text { The majority of learning is tacit knowledge and knowledge of } \\
\text { learning by doing. }\end{array}$ & \\
\hline & $\begin{array}{l}\text { It is important to pass the experience of some old experts to the } \\
\text { new employees. }\end{array}$ & \\
\hline \multirow{4}{*}{$\begin{array}{l}\text { Standardization, Systematization, } \\
\text { and Institutionalization of Knowledge }\end{array}$} & $\begin{array}{l}\text { We believe the "second screen construction" is similar to building } \\
\text { an electronic library. }\end{array}$ & \\
\hline & $\begin{array}{l}\text { The experiences of some old engineers do not fit modern technology. } \\
\text { They should be removed. }\end{array}$ & \\
\hline & $\begin{array}{l}\text { Only systematized knowledge is knowledge, or else it's } \\
\text { only information. }\end{array}$ & \\
\hline & $\begin{array}{l}\text { Institutionalization protocols should be formulated and defined for } \\
\text { archiving. Everyone should know what kind of knowledge should } \\
\text { be archived and what kind of knowledge is not necessary. }\end{array}$ & \\
\hline \multirow{3}{*}{ Problem-orientation } & The purpose of the systematization of knowledge is to apply it. & \multirow{11}{*}{$\begin{array}{l}\text { The Contextualization of the } \\
\text { Knowledge Application }\end{array}$} \\
\hline & $\begin{array}{l}\text { If knowledge management cannot solve a problem, such } \\
\text { management is just for show. }\end{array}$ & \\
\hline & $\begin{array}{l}\text { Business activities need to solve problems, knowledge management } \\
\text { is no exception. }\end{array}$ & \\
\hline \multirow{2}{*}{ To Serve Product Manufacturing } & $\begin{array}{l}\text { The second screen construction is for producing, managing the } \\
\text { problems in practice, and systematic archiving so as to easily solve } \\
\text { the problem of manufacturing at any time. }\end{array}$ & \\
\hline & $\begin{array}{l}\text { Significant knowledge comes from the work scene is summed up, } \\
\text { and then systematic feedback sent to the work scene. }\end{array}$ & \\
\hline \multirow{3}{*}{$\begin{array}{l}\text { The Contextualization of the } \\
\text { Knowledge Application }\end{array}$} & $\begin{array}{l}\text { Knowledge was blindly classified at the beginning, and later found } \\
\text { to be impractical. }\end{array}$ & \\
\hline & $\begin{array}{l}\text { Based on the context, the knowledge system is put to use to solve } \\
\text { the real problems, rendering the system much more practical. }\end{array}$ & \\
\hline & $\begin{array}{l}\text { Contextualization is a new form of knowledge categorization and } \\
\text { systematization. }\end{array}$ & \\
\hline \multirow{3}{*}{$\begin{array}{l}\text { To Turn Knowledge Management into } \\
\text { Work Norm and work routine }\end{array}$} & $\begin{array}{l}\text { At first, it was just campaign, and we gradually had the awareness } \\
\text { and habits of knowledge collation and knowledge categorization. }\end{array}$ & \\
\hline & $\begin{array}{c}\text { Now the progress of the second screen construction is checked } \\
\text { very regularly. }\end{array}$ & \\
\hline & $\begin{array}{l}\text { The Science and Technology Management Department will produce } \\
\text { a special report about the second screen construction. }\end{array}$ & \\
\hline \multirow{2}{*}{ Smart Enterprise } & $\begin{array}{l}\text { It is very important to get the support of senior leadership. } \\
\text { President He launched this campaign personally and paid much } \\
\text { attention to it. }\end{array}$ & \multirow{9}{*}{$\begin{array}{l}\text { Intelligentization of the } \\
\text { Knowledge Services }\end{array}$} \\
\hline & $\begin{array}{l}\text { The final goal of the second screen construction is certainly to } \\
\text { be intelligent. }\end{array}$ & \\
\hline \multirow[t]{2}{*}{$\begin{array}{l}\text { Intelligent Decision-making } \\
\text { Mechanism and Intelligent Error } \\
\text { Correction Method }\end{array}$} & $\begin{array}{l}\text { The ultimate goal and vision of "double screen innovation" is to } \\
\text { achieve an intelligent function of knowledge, such as intelligent } \\
\text { decision-making mechanism and intelligent error } \\
\text { correction method. }\end{array}$ & \\
\hline & Knowledge systems can help people make decisions. & \\
\hline \multirow{2}{*}{ Provide the Best Solution } & $\begin{array}{l}\text { For example, when one is undertaking an operation, there will be a } \\
\text { system to give you the choice of decision-making. }\end{array}$ & \\
\hline & $\begin{array}{l}\text { One can enter different variables of all kinds of restrictions and then } \\
\text { the system will formulate the best solution based on the } \\
\text { inputted condition. }\end{array}$ & \\
\hline \multirow{3}{*}{ Machine Learning } & $\begin{array}{l}\text { Now that high-tech is developing so quickly, knowledge } \\
\text { management should utilize the new technology very well. }\end{array}$ & \\
\hline & $\begin{array}{l}\text { Machine learning based on big data will promote the development } \\
\text { of knowledge management. }\end{array}$ & \\
\hline & $\begin{array}{l}\text { Machine learning can continue to iterate a more optimized system } \\
\text { to enhance the core competencies. }\end{array}$ & \\
\hline
\end{tabular}

Notes: Only parts of the two representative quotes for first-order and second-order categories are included because of space limitations. Additional quotes are available from the author. 


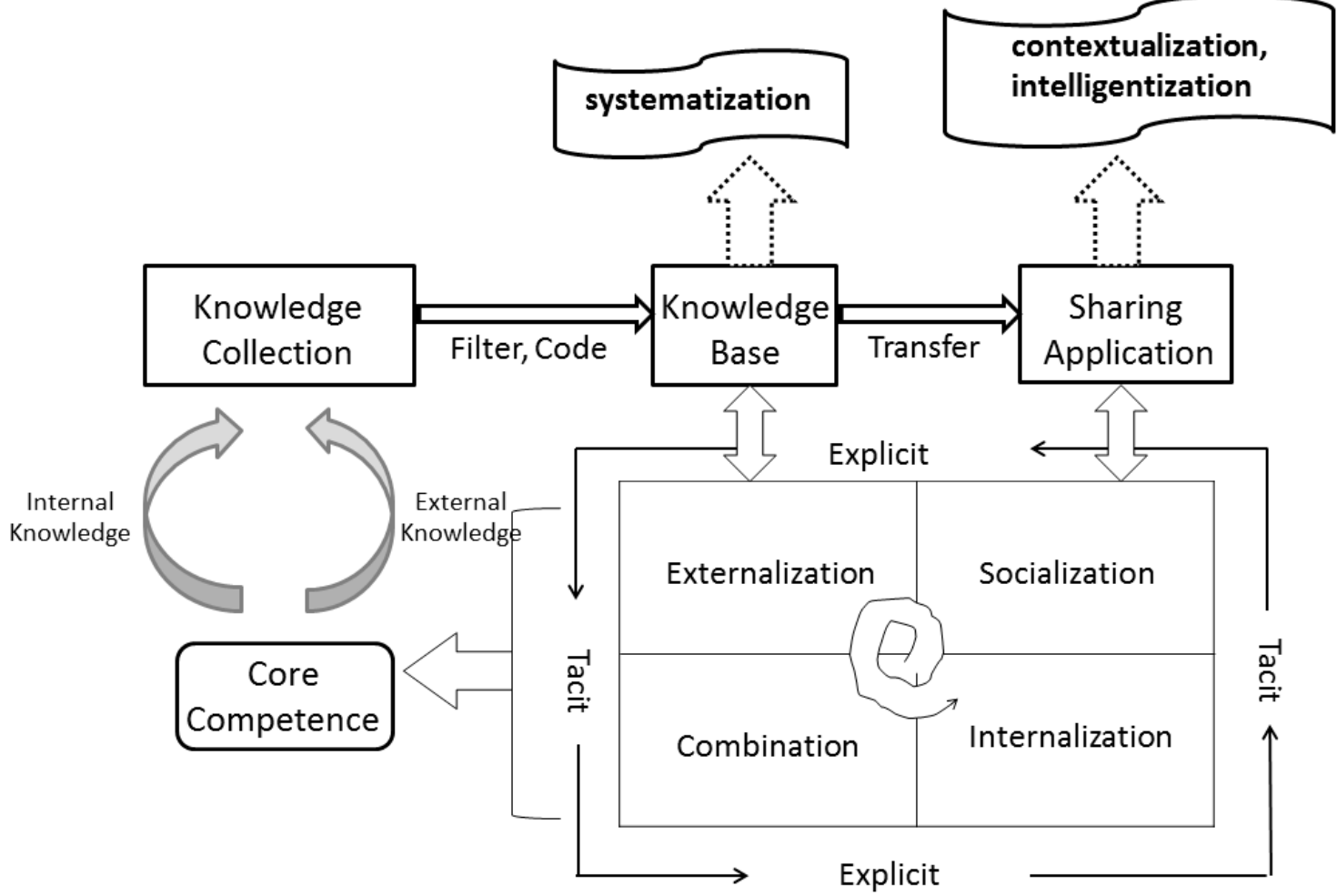

Figure 3. The knowledge management mode of Double Screen Innovation (DSI) (Source: Made by the author based on Nonaka's SECI model of knowledge management and the best practice of Commercial Aircraft Corporation of China Ltd.-COMAC).

\section{Discussions}

Organizational research traditionally attaches tremendous importance to a tangible economic asset whose values and attributes are assumed to be widely available and readily apparent to the people or firms being studied. Therefore, the author studied the mechanism of how knowledge has transformed into an important component of core competence.

The main outcome and contribution of this work is an inductive process model that puts forward a new concept of knowledge management named Double Screen Innovation (DSI). This paper clearly explains the special activity with a goal to improve the enterprise's knowledge management. This study documents how the DSI works in the implementation of knowledge management, also explains how the knowledge is co-created, accumulated and disseminated in real practice to create distinctive competencies.

In the course of developing the interactive knowledge management model, several new concepts with theoretical implications emerged. In particular, we propose the notions of the double screen innovation, knowledge engineering, and the systematization, contextualization, and intelligentization of knowledge.

To conclude, this paper offers two potential contributions to existing knowledge management and innovation literature. By identifying relevant features of knowledge management and the impact of knowledge on core competence-building, these findings enrich the set of antecedents that can be investigated in the future to better explain the drivers of core competence. It also contributes to a recent line of research in which knowledge-based core competence is shown to be increasingly important. A key outcome of this study is demonstrating how managers perceive and understand the knowledge, and its sources are also associated with how they go about searching for and acquiring knowledge, by explicating the linkages between conceptions of the significance and sources of useful knowledge, and subsequent knowledge acquisition and use processes. 


\subsection{Research Limitations}

One limitation is this study focus on interviewee accounts, in the form of interviews, as the main source of data. Wherever possible, however, we made it a point to engage interviewees in-situ. For instance, if an interviewee spoke about a manufacturing issue, we made concerted efforts to see the actual process in action or the solution implemented. We attempted to study knowledge management in action to the greatest extent possible- that is, by spending time observing real-life situations that managers have to deal with. A follow-up to this study would perhaps involve fewer key persons and spend a greater amount of time inside those departments, which would offer more effective and systematic observations of the micro-level actions and interactions undertaken by managers and other organization members as they handle situations in real time. As a corollary to this observation, it also would have been desirable to engage with the firm's suppliers, competitors, and customers to get an exogenous view of the processes. Nevertheless, we limited the scope of this study to closely study the internal processes of the management and the company.

The focus on a single firm could also be seen as a limitation, but the single firm focus does allow for an in-depth understanding of the drivers of knowledge management and the process of the core competence-building, which would be difficult to accomplish in the study of another company.

For simplicity and clarity of exposition, however, we limited the description of the findings to unidirectional associations. Longitudinal studies might be better able to shed light on how knowledgeable practice can be recursively associated with changes in executive knowledge before gradually gaining consensus among members within the company. Studying the evolution of knowledge management and the relationship between it and core competence building over time could offer rich opportunities for a better understanding of how knowledge shapes the foundations of sustained competitive advantage.

\subsection{Suggestions for Future Research}

Looking into the future, the research on knowledge management at COMAC provides inspirations for both theory and practice. On the one hand, existing scholar research primarily emphasizes the theory and practice of competitive advantage in the open and digital era. For example, the classic saying goes that competitive advantage has a great deal to do with the right choice of industry and strategic positioning within that industry [37]. Drucker [38] predicted that it is crucial to pay significant attention to the importance of knowledge and that crafting competitive advantage has a lot to do with developing distinctive knowledge as a strategic resource, which has been recognized more broadly in the big data era of today $[3,10,12]$. Barney $[17,24]$ identified four characteristics to evaluate resources, value, rareness, cost of imitation, and non-substitutability. However, studies related to the resource-based view (RBV) usually treat these attributes as exogenous to the decision-making process of organizational leaders. The research on the origins of competitive advantage is beginning to indicate a deeper appreciation of managers as active, knowledgeable agents [14,39]. This study shows how knowledge becomes a resource that can transform internal and external data into common knowledge, and its application to uncommon uses and management decision-making process. It is important to research how organizational leaders can create new interactive and intelligent systems that empower teams and individuals to co-create and make the best of knowledge in their daily work-particularly because this aspect has not been fully researched yet. Findings from this study concerning both executive and engineering knowledge could expand future research on the origins of organizational resources and capabilities.

On the other hand, based on the company's knowledge management experience, DSI helps the enhancement of the management capability and core product development, while propelling technological innovation as well. Given that core competence-building is the ultimate purpose of DSI-naturally, it would promote knowledge sharing and innovation. It is very important to construct a firm innovation system based on the core competence of knowledge management [40]. Adherence to DSI will not only play a crucial role in promoting values for enhancing the core 
technology and breakthroughs of this industry and enriching the construction of the commercial aircraft discipline system, but also enlightens the big data management and knowledge management in any other industries, providing a promising future of corporate core-competence building and dynamic capability evolution.

\section{Conclusions}

Drawing from literature of knowledge management and knowledge-based view theory, this paper elaborates how a new type of knowledge management practice represented by the case of Double Screen Innovation (DSI) from the Commercial Aircraft Corporation of China Ltd. (COMAC) could help enterprises build sustainable core competence, which provides new perspectives and ideas for multi-level knowledge management beneficial to business sustainability in the era of big data. DSI, as a novel way of knowledge management, optimizes the micro-level knowledge creation and sharing, and macro-level organizational learning mechanisms to meet the core needs of internal and external systems, scenarios, circumstances, and intelligence. The process of knowledge creation, transformation, and application helps to integrates and transform big data into useful business information, and thus provides an endless driving force to the establishment and promotion of the corporate core competencies.

\section{Implications}

This research has some useful implications for practicing managers. The study shows that in an industry with extremely high technological entry barrier and one threatened by strong international competition, very intensive knowledge, technology, and innovation are needed as the foundation for future development. Therefore, a useful insight for practicing managers might be that given the complexity of their work and daily routines, they should find the right direction for future development and continue to focus on core competence-building. They should develop unique ways to manage the knowledge well without having to spend an inordinate amount of time doing work unrelated to the knowledge-based core competence. In simple terms, the purpose is to lay a solid knowledge foundation for core competence-building and advocate the whole enterprise to value the importance of knowledge management. This study builds on this observation and notes that staffs at COMAC increased their efforts to acquire knowledge from both independent R\&D and external sources. Based on the company's knowledge and experience accumulation, DSI really helped strengthen the capability of management and core products development, while engendering scientific and technological transformation as well. Given that core competence-building is the ultimate purpose of DSI, an enterprise that applies the DSI model should also work together with their suppliers throughout the value chain to co-create and share the knowledge. This DIS will not only be critical in promoting values for enhancing the core technology and breakthroughs of this industry and bolstering the establishment of the commercial aircraft discipline system, but also enlightens the big data management and knowledge management in any other industries, providing a promising future in corporate core-competence building and dynamic capability evolution.

\subsection{Implications for Practice}

The development and application of DSI is not only a simple linear development, but a parallel progress. Several important aspects demand extra attention and effort in the future.

\subsubsection{Create DSI Based Core Competencies}

Through DSI, COMAC aims to enhance the management level, assist production model development, and promote scientific and technological innovation. As a means of knowledge management, COMAC's DSI promotes the organization of resources, the accumulation of capacity, knowledge transfer, and the strengthening of learning. Under the background of intelligent development, knowledge base and management become the key to corporate core competence, 
and DSI is the central embodiment and application of the knowledge-based core competence. As a concentrated expression and application of the knowledge-based core competence theory, DSI includes many different aspects, such as the establishment of knowledge classification system, improvement of the knowledge management system, promotion of the normalization of tacit knowledge and establishment of an explicit knowledge system, increased attention to the knowledge contextualization and platform establishment, and explorations in the creation of intelligent knowledge management system, all of which are designed to better serve the building of the corporate core competencies.

\subsubsection{Establish Problem-Solving and Application-Oriented DSI Management Model}

Knowledge management for problem-solving and applications in real-life scenarios is the original intention of DSI. The principle of beginning with the end in mind should be upheld during the early days of the establishment of a knowledge system, combining knowledge creation with problem-solving and application-oriented integration during the entire process. The second screen construction should in line with the goal to promote product development, model production, and manufacturing line in the practical problems, including pre-research records, technology maturity development, process transformation, process validation, and technological innovation in different aspects by using real innovation to solve the problem.

\subsubsection{Optimize the Management Decision Mechanism and Mass Participation Mechanism of DSI}

The responsibility of the top management team leaders is to ensure the implementation of DSI strategy from top to bottom, and that the construction of a second screen should be brought into the assessment mechanism and incentive mechanism to stimulate employees from all departments, as well as the continuation of implementation in the long run. Mass participation will produce unexpected ideas and novel knowledge. Take Shanghai Aircraft Manufacturing Company as an example, more than 37,000 knowledge items are contributed each year, with 12 knowledge items contributed per capita. It is such mass participation and mass creation under leadership by top executives within the company that ensures the strong and effective implementation of DSI.

\subsubsection{Achieve an Internal and External Knowledge Integrated System Led by DSI}

The implementation of DSI also requires the support of open innovation as an important complement to internal knowledge, especially in the forms of inspiration and wisdom from the government, research institutions, suppliers, users, and other stakeholders. Companies can benefit from understanding their own knowledge level and abilities within the business innovation ecosystem. By absorbing and digesting new information, and internalizing the company's knowledge assets, an enterprise's core capacity and innovation strategy can be better implemented.

\subsection{Implications for Knowledge Management and Sustainability}

Knowledge management is the key to achieve sustainable business performance and industry sustainability [5,41]. As pointed by Centobelli, Cerchione, and Esposito [13], one of the important gaps in knowledge management research is the lack of a comprehensive taxonomy of knowledge management systems that may support the processes of knowledge creation, acquisition, storage, transfer, sharing and application. Regarding this aspect, this study is useful for scholars and managers who are seeking to uncover the secrets to innovation that is the keystone in the process of building a knowledge creating company. As argued by knowledge management scholars [8,9,27], successful companies are those that consistently create knowledge, widely disseminate such knowledge throughout the organization, and quickly incorporate such knowledge in new technologies and products. These activities define a "knowledge-creating" company, whose sole business is continuous innovation through knowledge management [9]. However, even though the knowledge is the key source of innovation, the routine and methods of creating and disseminating knowledge throughout the organization as a long-term driving force for competitive advantage remained to be explored [13,26]. Scholars and researchers can 
develop a better appreciation of why some firms seek more knowledge and use unique knowledge to build core competence for sustainable development in better ways than others.

Author Contributions: Conceptualization, X.Y., C.Z.; Investigation, C.Z., J.C.; Formal analysis, X.Y., C.Z.; Funding acquisition, J.C.; Methodology, X.Y., C.Z.; Project administration, J.C.; Supervision, J.C.; Writing—original draft, X.Y. and C.Z.; Writing-review \& editing, X.Y. and C.Z.

Funding: This research was funded by the Major Program of National Fund of Philosophy and Social Science of China (Grant Number:17ZDA082) and the National Natural Science Foundation of China (Grant Number: 71941026).

Conflicts of Interest: The authors declare no conflict of interest.

\section{Abbreviations}

Glossary for abbreviations used in this manuscript.

$\begin{array}{ll}\text { Number } & \text { Abbreviations } \\ 1 & \text { COMAC } \\ 2 & \text { DSI } \\ 3 & \text { RBV } \\ 4 & \text { KBV } \\ 5 & \text { R\&D } \\ 6 & \text { ERP } \\ 7 & \text { CNKI } \\ 8 & \text { KM } \\ 9 & \text { SECI }\end{array}$

\section{Full Name}

Commercial Aircraft Corporation of China Ltd.

Double Screen Innovation

Resource-Based View

Knowledge-Based View

Research and Development

Enterprise Resource Planning

China National Knowledge Infrastructure

Knowledge Management

Socialization, Externalization, Combination and

Internalization

\section{References}

1. Schumpeter, J.A. Theory of Economic Development, New ed.; Routledge: New Brunswick, NJ, USA, 1934; ISBN 978-0-87855-698-4.

2. Etzion, D.; Aragon-Correa, J.A. Big Data, Management, and Sustainability: Strategic Opportunities Ahead. Organ. Environ. 2016, 29, 147-155. [CrossRef]

3. George, G.; Haas, M.R.; Pentland, A. Big Data and Management. Acad. Manag. J. 2014, 57, 321-326. [CrossRef]

4. Leydesdorff, L. The Triple Helix, Quadruple Helix, . . , and an N-Tuple of Helices: Explanatory Models for Analyzing the Knowledge-Based Economy. J. Knowl. Econ. 2012, 3, 25-35. [CrossRef]

5. Pablos, P.O.; Lytras, M. Knowledge Management, Innovation and Big Data: Implications for Sustainability, Policy Making and Competitiveness. Sustain. Basel 2018, 10, 2073. [CrossRef]

6. Erkut, B. The Emergence of the ERP Software Market between Product Innovation and Market Shaping. J. Open Innov. Technol. Mark. Complex. 2018, 4, 23. [CrossRef]

7. Von Krogh, G. Artificial Intelligence in Organizations: New Opportunities for Phenomenon-Based Theorizing. Acad. Manag. Discov. 2018, 4, 404-409. [CrossRef]

8. Nonaka, I.; Toyama, R.; Nagata, A. A firm as a knowledge-creating entity: A new perspective on the theory of the firm. Ind. Corp. Chang. 2000, 9, 1-20. [CrossRef]

9. Nonaka, I. Harvard Business Review; Harvard Business School Press: Boston, MA, USA, 2007.

10. McAfee, A.; Brynjolfsson, E. Big data: The management revolution. Harv. Bus. Rev. 2012, 90, 60-68.

11. Barley, W.C.; Treem, J.W.; Kuhn, T. Valuing Multiple Trajectories of Knowledge: A Critical Review and Agenda for Knowledge Management Research. Annals 2018, 12, 278-317. [CrossRef]

12. Grant, R.M. Toward a knowledge-based theory of the firm. Strateg. Manag. J. 1996, 17, 109-122. [CrossRef]

13. Centobelli, P.; Cerchione, R.; Esposito, E. Knowledge Management in Startups: Systematic Literature Review and Future Research Agenda. Sustainability 2017, 9, 361. [CrossRef]

14. Augier, M.; Teece, D.J. Dynamic Capabilities and the Role of Managers in Business Strategy and Economic Performance. Organ. Sci. 2009, 20, 410-421. [CrossRef] 
15. Bansal, T. Guidepost: Sustainable Development in an Age of Disruption. Acad. Manag. Discov. 2019, 5, 8-12. [CrossRef]

16. Barney, J. Firm Resources and Sustained Competitive Advantage. J. Manag. 1991, 17, 99-120. [CrossRef]

17. Priem, R.L.; Butler, J.E. Is the Resource-Based “View” a Useful Perspective for Strategic Management Research. Acad. Manag. Rev. 2001, 26, 22-40.

18. Anand, N.; Gardner, H.K.; Morris, T. Knowledge-based innovation: Emergence and embedding of new practice areas in management consulting firms. Acad. Manag. J. 2007, 50, 406-428. [CrossRef]

19. Kogut, B.; Zander, U. Knowledge of the Firm, Combinative Capabilities, and the Replication of Technology. Organ. Sci. 1992, 3, 383-397. [CrossRef]

20. Martinkenaite, I.; Breunig, K.J. The emergence of absorptive capacity through micro-macro level interactions. J. Bus. Res. 2016, 69, 700-708. [CrossRef]

21. Wernerfelt, B. A resource-based view of the firm. Strateg. Manag. J. 1984, 5, 171-180. [CrossRef]

22. Bhatt, G.D. Knowledge management in organizations: Examining the interaction between technologies, techniques, and people. J. Knowl. Manag. 2001, 5, 68-75. [CrossRef]

23. Flor, M.L.; Cooper, S.Y.; Oltra, M.J. External knowledge search, absorptive capacity and radical innovation in high-technology firms. Eur. Manag. J. 2018, 36, 183-194. [CrossRef]

24. Zhang, J.; Wang, Y.; Zhang, M.Y. Team Leaders Matter in Knowledge Sharing: A Cross-Level Analysis of the Interplay between Leaders and Members Goal Orientations in the Chinese Context. Manag. Organ. Rev. 2018, 14, 715-745. [CrossRef]

25. Meng, D.; Li, X.; Rong, K. Industry-to-university knowledge transfer in ecosystem-based academic entrepreneurship: Case study of automotive dynamics \& control group in Tsinghua University. Technol. Forecast. Soc. Chang. 2019, 141, 249-262.

26. Cerchione, R.; Esposito, E.; Spadaro, M.R. A literature review on knowledge management in SMEs. Knowl. Manag. Res. Pract. 2016, 14, 169-177. [CrossRef]

27. Chen, J.; Tong, L.; Ngai, E.W.T. Inter-organizational knowledge management in complex products and systems: Challenges and an exploratory framework. J. Technol. Manag. China 2007, 2, 134-144. [CrossRef]

28. Chen, J.; Chen, Y.; Du, X.; Li, C.; Lu, J.; Zhao, S.; Zhou, X. Big data challenge: A data management perspective. Front. Comput. Sci. 2013, 7, 157-164. [CrossRef]

29. Lewis, M.W.; Grimes, A.J. Metatriangulation: Building Theory from Multiple Paradigms. Acad. Manag. Rev. 1999, 24, 672-690. [CrossRef]

30. Yin, R.K. Case Study Research and Applications: Design and Methods, 6th ed.; Sage Publications: Thousand Oaks, CA, USA, 2017; ISBN 978-1-5063-3616-9.

31. Strauss, A.; Corbin, J.M. Basics of Qualitative Research: Techniques and Procedures for Developing Grounded Theory, 2nd ed.; Sage Publications: Thousand Oaks, CA, USA, 1998; ISBN 978-0-8039-5940-8.

32. Miles, M.B.; Huberman, A.M.; Saldaña, J. Qualitative Data Analysis: A Methods Sourcebook, 3rd ed.; Sage Publications: Thousand Oaks, CA, USA, 2014; ISBN 978-1-4522-5787-7.

33. Glaser, B. Discovery of Grounded Theory: Strategies for Qualitative Research; Routledge: Abingdon, UK, 2017; ISBN 978-1-351-52216-8.

34. Eisenhardt, K.M. Building Theories from Case Study Research. Acad. Manag. Rev. 1989, 14, 532-550. [CrossRef]

35. Chen, H.; Chiang, R.H.L.; Storey, V.C. Business Intelligence and Analytics: From Big Data to Big Impact. MIS Q. 2012, 36, 1165-1188. [CrossRef]

36. Gandomi, A.; Haider, M. Beyond the hype: Big data concepts, methods, and analytics. Int. J. Inf. Manag. 2015, 35, 137-144. [CrossRef]

37. Porter, M.E. Competitive Strategy: Techniques for Analyzing Industries and Competitors; Social Science Research Network: Rochester, NY, USA, 1980.

38. Drucker, P.F. Innovation and Entrepreneurship, Reprint ed.; HarperCollins e-books: New York, NY, USA, 2009.

39. Baum, D.A.; Smith, S.D.; Donovan, S.S.S. The Tree-Thinking Challenge. Science 2005, 310, 979-980. [CrossRef] 
40. Adner, R.; Kapoor, R. Value creation in innovation ecosystems: How the structure of technological interdependence affects firm performance in new technology generations. Strateg. Manag. J. 2010, 31, 306-333. [CrossRef]

41. Abbas, J.; Hussain, I.; Hussain, S.; Akram, S.; Shaheen, I.; Niu, B. The Impact of Knowledge Sharing and Innovation on Sustainable Performance in Islamic Banks: A Mediation Analysis through a SEM Approach. Sustainability 2019, 11, 4049. [CrossRef]

(c)

(C) 2019 by the authors. Licensee MDPI, Basel, Switzerland. This article is an open access article distributed under the terms and conditions of the Creative Commons Attribution (CC BY) license (http://creativecommons.org/licenses/by/4.0/). 